\title{
QTL ANALYSIS OF DEHYDRATION TOLERANCE AT SEEDLING STAGE IN RICE (ORYZA SATIVA L.)
}

\author{
Ranawake $\mathrm{AL}^{1,2 *}$ Nakamura $\mathrm{C}^{2}$ \\ ${ }^{1}$ Department of Agricultural Biology, Faculty of Agriculture, university of Ruhuna, Sri Lanka \\ ${ }^{2}$ Laboratory of Plant Genetics, Department of Agro-environmental Science, Graduate School of Agricultural \\ Science, Kobe University, Japan
}

Accepted: 4 June 2012

\begin{abstract}
Dehydration tolerant QTLs at the seedling stage in rice (Oryza sativa L.) was studied using green shoot length as a parameter, which was measured during the recovery period after dehydration stress. According to the results of pilot experiment carried out to evaluate the two parental rice cultivars for the level of dehydration tolerance, at 4 day and 5-day dehydration stress, Japonica parent Hyogokithanishiki (HGKN) showed more tolerance than that of Hokuriku-142 Indica parent (HOK). Quantitative trait loci (QTLs) associated with dehydration tolerance was identified using 163 recombinant inbred lines derived from these parents on a linkage map constructed with 95 simple sequence repeat (SSR) markers. Three dehydration tolerant minor QTLs were identified on chromosome 1,2 and 3 at composite interval mapping by WinQTLCARTOGRAHER. According to the additive effect plots the QTLs on chromosome 1 and 2 have the allelic effect from the Indica parent Hokuriku-142 and QTL on chromosome 3 has allelic effect from Hyogokithanishiki Japonica parent. However, according to the 1000 time permutation test, these QTLs didn't exceed the threshold LOD value.
\end{abstract}

Key words: Dehydration tolerance, QTL, rice (Oryza sativa L.), SSR markers

\section{INTRODUCTION}

Drought stress is the most common adverse environmental condition that can seriously reduce crop productivity. Increasing crop resistance to drought stress would be the most economical approach to improve agricultural productivity and to reduce agricultural use of fresh water resources. Cultivated rice (Oryza sativa L.) demands tremendous amount of water during growth. Development of new rice cultivars with drought tolerance saves a great amount of water and also helps to increase yield stability. Drought resistance in rice depends on one or more factors of the following components: ability of roots to exploit deep soil water, the capacity for osmotic adjustment and the ability to control and reduce water loss (Ngueyen et al. 2004). Drought tolerant rice cultivars exhibit various adaptations such as earlymaturity, flowering even under little or no rain, stop growing as soil moisture declines, leaf rolling and response of root distribution to soil drying (Azhiri-Sigari et al. 2000).

\footnotetext{
*Corresponding author: lankaranawake@agbio.ruh.ac.lk
}

However, drought tolerance is unmanageable to molecular genetics studies mainly due to limited awareness of specific traits linked to drought tolerance. Furthermore, it is difficult to conduct drought stress treatments in a quantitative and reproducible way. These difficulties have significantly impeded research on plant drought tolerance. Limited awareness of plant phenotypes specifically conferred by drought stress has prevented researchers from using traditional genetics approaches to directly study drought stress tolerance (Tripathy et al. 2000). The biological basis for drought tolerance is still largely unknown and few drought tolerance determinants have been identified (Ludlow and Muchow, 1990; Bohnert et al. 1995; Araus et al. 2002; Bruce et al. 2002). Undisclosed drought tolerance mechanism has stagnated both traditional breeding efforts and use of modern genetics approaches in the improvement of drought tolerance of crop plants (Passioura 2010; Sinclair 2011).

Despite the lack of understanding of drought tolerance mechanisms, physiological and mo- 
lecular biological studies have documented several plant responses to drought stress (Bohnert et al. 1995; Blum, 1996; Ingram and Bartel, 1996; Bray, 1997; Schroeder et al. 2001; Luan, 2002; Sharp et al. 2004; Xiong et al. 2006). Molecular approaches to develop drought tolerant rice cultivar have been applied by QTL analysis. Integration of publicly available rice genetic map covered by microsatellite markers with trait data of diverse mapping populations has been successfully identified chromosomal regions associated with some secondary traits of drought response, such as osmotic adjustment (Lilley et al. 1996; Zhang et al. 1999, 2001; Robin et al. 2003), cell membrane stability (Tripathy et al. 2000), abscisic acid (ABA) content (Quarrie et al. 1994, 1997), stomatal regulation (Price et al. 1997), leaf water status, and root morphology (Champoux et al. 1995; Ray et al. 1996; Price and Tomos 1997; Yadav et al. 1997; Ali et al. 2000; Courtois et al. 2000; Zheng et al. 2000; Zhang et al. 2001; Kamoshita et al. 2002; Price et al. 2002), membrane stability and osmotic adjustment (Li et al. 2005), leaf size and ABA accumulation (Robbin et al. 2003).

Wang et al. (2004) showed the reduction in shoot height under dehydration stress in dehydration susceptible rice cultivar, CT9993 while dehydration tolerant IR2266 was not affected. Genomic regions of rice chromosomes with drought-resistant loci have been reported by Adam et al. (2002), Tripathy et al. (2000), Zeng et al. (2000).

In the present study we used $\mathrm{F}_{6}$ generation of inbred line population for QTL analysis at the seedling stage. The Indica parental cultivar, Hokurikuriku-142 and Japonica parental cultivar, Hyogo-kithanishiki are genetically divergent types, which provides enough segregation of both molecular marker alleles and ergonomically important genes for QTL analysis. The drought tolerant data were collected according to Ranawake and Nakamura (2011). The objective of this study was to investigate the effectiveness of new breeding materials for rice dehydration tolerant through genetic re- combination between Indica and Japonica rice that have no previous evidence on drought tolerant traits.

\section{MATERIALS AND METHODS}

$\mathrm{F}_{6}$ generation of 163 recombinant inbred line (RIL) population derived from Japonica rice cultivar, Hyogo-Kithanishiki (HGKN), and an Indica rice cultivar, Hokuriku-142 (HOK) were used for QTL analysis. Hokuriku was bred from a cross between a Korean cultivar, 'Milyang 21 and an IRRI line 'IR-2061-21431 in the Hokuriku Agricultural Experimental station, Japan (Misawa et al. 2000).

Evaluation of inbred line population for dehydration tolerance: Two week old rice seedlings were undergone a 5 day drying period. Five-day after complete drying plants were watered and 10 days after recovery period plants were evaluated for drought tolerance (Ranawake and Nakamura 2011). Experiment was carried out according to the complete randomized block design and repeated three times. Average green shoot length was used as the parameter to evaluate the inbred line population on the $10^{\text {th }}$ day of the recovery period followed by 5-day dehydration stress.

DNA extraction, marker genotyping and construction of linkage map: DNA extraction was done and primer pairs for rice microsatellites (simple sequence repeat: SSR) were surveyed for polymorphisms. The linkage map was constructed using MAPMAKER 3.0, for 100 SSR markers. Composite interval mapping was performed to identify significant QTLs with forward-backward regression. The experiment-wise LOD threshold level was determined by computing 1,000 permutations, as implemented by the WinQTLCARTOGRAHER (Wang et al. 2003 http://statgen.ncsu.edu/ qtlcart/WinQTLCart). These permutations can account for non-normality in marker distribution and trait values. The level of significant LOD value for QTLs in this study was determined to be 3.01 at $p<0.05$. 


\section{RESULTS AND DISCUSSION}

Evaluation of two parental rice cultivars for dehydration tolerance: Considering the fact that two parental cultivars showed the highest significant difference in the green shoot length at 5-day dehydration stress, this stress condition was decided to apply for the evaluation of RILs (Fig.1).

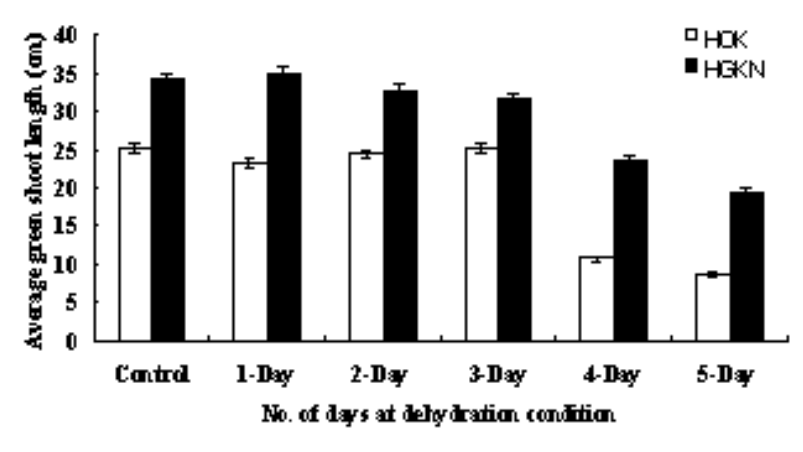

Fig. 1: Mean length of green shoot of seedlings survived after dehydration stress for 1-5 days in two parental cultivars. Data were taken at the $10^{\text {th }}$ day of recovery period after the indicated period of dehydration stress. Twenty seedlings of each parent were subjected to the dehydration stress and the experiment was repeated three times. Bars indicate standard errors.

Evaluation of inbred line population for dehydration tolerance: The frequency distribution of average green shoot length in the RIL population on the $10^{\text {th }}$ day of the recovery period after 5-day completely drying period showed a transgressive segregation in both directions (Fig. 2). This indicates that the alleles for drought tolerance in the population have donated from both drought tolerant parent and drought susceptible parent.

QTL analysis of dehydration tolerance in inbred line population: QTL analysis was performed using WinQTLCARTOGRAHER version 2.0 (Wang et. al, 2003). To understand the significance of these QTLs, composite interval mapping was performed. Minor dehydration tolerant QTLs with LOD score more than 2 were detected on chromosome 1 , 2 and 3 at composite interval mapping of the present study (Fig.3, Fig. 4). A total of $24 \%$

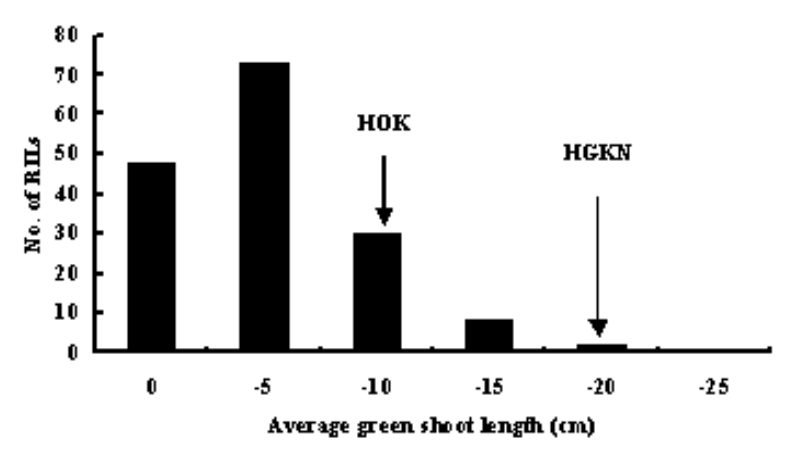

Fig. 2: Frequency distribution of the RILs after 5day dehydration period. Data were taken on the $10^{\text {th }}$ day of the recovery period after 5-day dehydration stress. Twenty seedlings of each parent were subjected to the dehydration stress and experiment was repeated three times

of phenotypic variation has been explained by these 3 QTLs collectively (Table1). Drought tolerant QTLs on chromosome 1 and 2 have acquired drought tolerant alleles from drought susceptible parent Hokuriku while the reported strongest drought tolerant QTL on chromosome 3 possesses tolerant alleles from Hyogokithanishiki parent(Table1).

According to additive effect plots depicted in the composite interval map plot, the QTLs on chromosome 1 and 2 had the allelic effect from the Indica parent Hokuriku-142 and QTL on chromosome 3 had allelic effect from Hyogokithanishiki Japonica parent (Table 1).

There are many evidences on presence of drought tolerant candidate regions on chromosome 1, 2 and 3. RFLP linkage map for Co39 $\mathrm{x}$ Moroberekan recombinant inbred population which was used for QTL analysis for osmotic adjustment and lethal osmotic potential also indicated that chromosomes 1 and 3, possess the QTLs associated with root characters (Champoux el al., 1995). Wang, et al. (2005) has been selected rice chromosome 1 for identification of candidate genes for drought stress tolerance in rice. Price et al., (2002) and Lafitte et al., (2002) also give evidence on presence of drought tolerant QTLs on chromosome 1. In the region of RM472-RM104 on chromosome 1, drought tolerant QTLs for 
D ICE
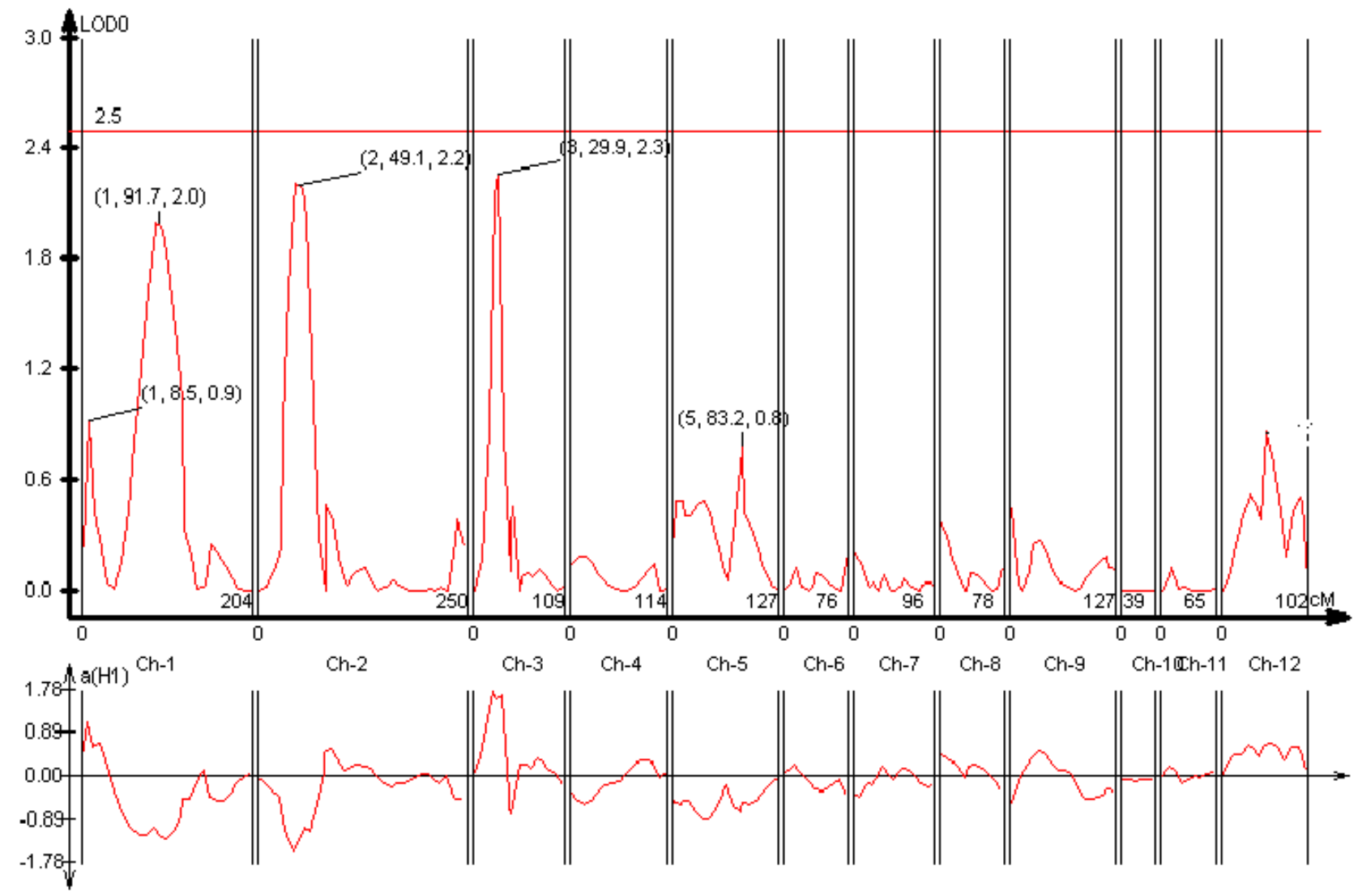

Fig. 3: QTLs controlling dehydration tolerance at the seedling stage identified by the composite interval mapping in the 5-day dehydration stress

root volume and number of days to leaf rolling were detected by Yue et al., (2006). QTL were also identified for root thickness and root weight (Zheng et al. 2000), as well as for relative water content, leaf rolling, and leafdrying score (Babu et al. 2003) under drought stress. Further, a total of three QTLs on chromosomes 2, 4, and 7 were detected for relative growth rate in rice (Kato et al. 2008).

Chromosome 2 was found to be associated with the grain yield or yield components un-
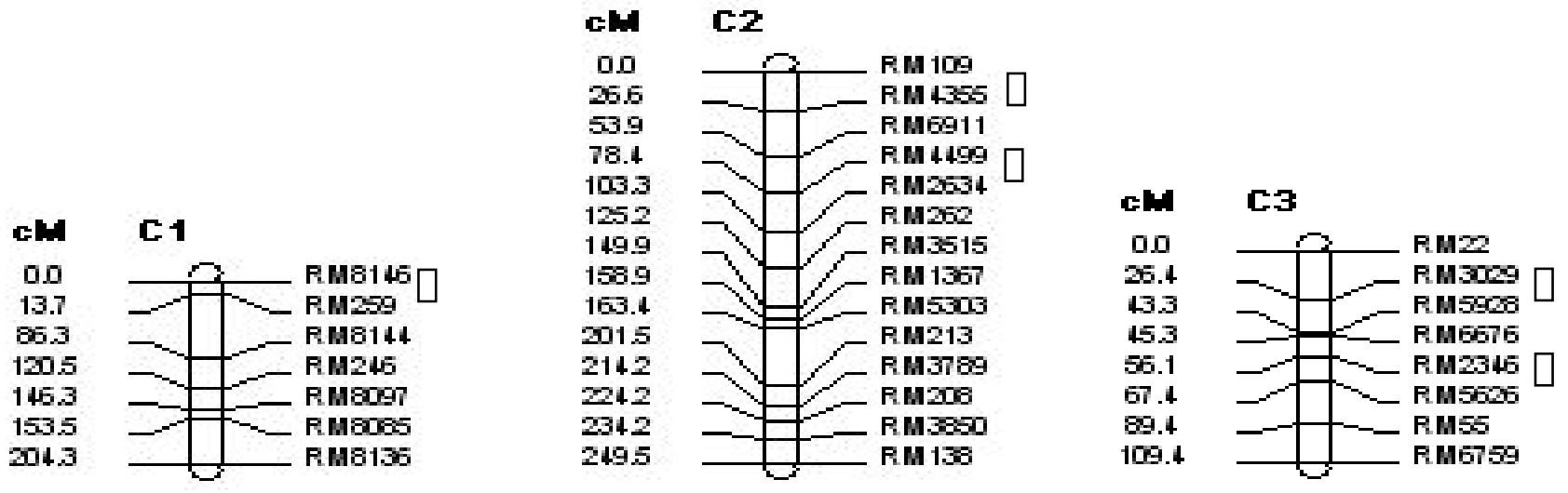

Fig. 3: QTLs controlling dehydration tolerance at the seedling stage identified by the composite interval mapping in the 5-day dehydration stress 
der drought stress conditions by Yue et al. (2008). Yue et al. (2008) has also reported presence of drought resistant QTLs both on long arm and short arm of the chromosome 3 for flag leaf length, flag leaf width and plant height under drought stress. This chromosomal region on chromosome 3 coincides with the same chromosomal regions where we detected minor QTL on chromosome 3 (Table 1). These all findings align with the findings of our study at least proving that rice chromosomes 1, 2 and 3 are responsible for drought tolerance at the seedling stage.

Table 1: Dehydration tolerant QTLs found at composite interval mapping

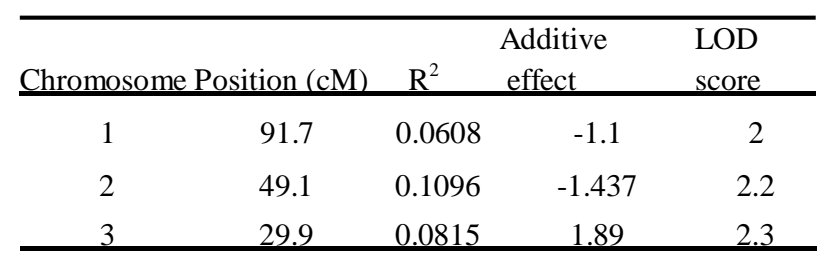

$\mathrm{cM}=$ Centimogon distance of chromosome

However considering background genetic effect, these QTLs do not exceed threshold LOD value computed by the 1000 time permutation test in WinQTLCARTOGRAHER version 2.5. According to results of QTL analysis there was a narrow variation in the detected QTLs for dehydration tolerance. This might be the reason that two parental rice cultivars had narrow but significant difference at the level of dehydration tolerance which was not wide enough to detect strong dehydration tolerant QTLs.

\section{REFERENCES}

Adam H, Towend J, Jones MP, Audebert A and Courtois B 2002 Mapping of QTLs associated with drought avoidance in upland rice grown in the Phillipines and West Africa. Plant Mol. Biol.48: 683-695.

Ali ML, Pathan MS, Zhang J, Bai G and Sarkarung S et al. 2000 Mapping QTLs for root traits in a recombinant inbred population from two Indica ecotypes in rice. Theor. Appl. Genet.101: 756766.
Araus JL, Slafer GA, Reynolds MP and Royo C 2002 Plant breeding and drought in C3 cereals: What should we breed for?. Ann Bot (Lond). 89: 925 -940 .

Azhiri-Sigari T, Yamaguchi A, Kamoshita A and Wade 12000 Genotypic variation in response of rainfed lowland rice to drought and rewatering II. Root growth. Plant Production Sci. 3: 180-188.

Babu RC, Nguyen BD, Chamarerk V, Shanmugasundaram $\mathrm{P}$, Chezhian $\mathrm{P}$ et al., 2003. Genetic analysis of drought resistance in rice by molecular markers: association between secondary traits and field performance. Crop Sci. 43: $1457-$ 1469.

Blum A 1996 Crop responses to drought and the interpretation of adaptation. J. Plant Growth Regul. 20: $135-148$.

Bohnert HJ, Nelson DE and Jensen RG 1995 Adaptations to environmental stresses. Plant Cell. 7: 1099-1111.

Bray EA 1997 Plant responses to water deficit. Trends Plant Sci. 2: 48-54.

Bruce WB, Edmeades GO and Barker TC 2002 Molecular and physiological approaches to maize improvement for drought tolerance. J. Exp. Bot. 53: 13-25

Champoux MC, Wang G, Sarkarung S, Mackill DJ, OToole JC, Huang N and McCouch SR 1995 Locating genes associated with root morphology and drought avoidance in rice via linkage to molecular markers. Theoretical and Applied Genetics. 90: 756-766.

Courtois B, McLaren G, Sinha P K, Prasad K and Yadav R et al. 2000 Mapping QTLs associated with drought avoidance in upland rice. Mol. Breed. 6: 55-66.

Ingram J and Bartel D 1996 The molecular basis of dehydration tolerance in plants. Annu. Rev. Plant Physiol. Plant Mol. Biol. 47: 377-403.

Kamoshita A, Wade J, Ali L, Pathan S and Zhang J et al. 2002 Mapping QTLs for root morphology of a rice population adapted to rainfed lowland conditions. Theor. Appl. Genet. 104: 880-893.

Kato Y, Hirotsu S, Nemoto K and Yamagishi J 2008 Identification of QTLs controlling rice drought tolerance at seedling stage in hydroponic culture. 160 (3): 423-430.

Lafitte HR, Courtois B and Arraudeau M 2002 Genetic improvement of rice in aerobic systems: progress from yield to genes. Field Crops Res.75:171-190.

Li Z, Mu P, Li C, Zhang H, Li Z, Gao Y and Wang X 2005 QTL mapping of root traits in a double haploid population from a cross between upland and lowland Japonica rice in three environments. Theor. Appl. Genet.110: 1244-1252.

Lilley JM, Ludlow M, McCouch S and O'Toole JC 
RICE

1996 Locating QTL for osmotic adjustment and dehydration tolerance in rice. J. Exp. Bot. 47: 1427-1436.

Luan S 2002 Signaling drought in guard cells. Plant Cell Environ. 25: 229-237

Ludlow MM and Muchow RC 1990 A critical evaluation of traits for improving crop yields under water-limited environments. Adv. Agron. 43: 107-153.

Misawa S, Mori N, Takumi S, Yoshida S and Nakamura C 2000 Mapping of QTLs for low temperature response in seedlings of rice (Oryza sativa L.). Cereal Res. Communi. 28: 33-40.

Ngueyen TTT, Klueva N, Chamarek V, Aarti A, Magpantay G, Millen ACM, Pathan MS and Nguyen HT 2004 Saturation mapping of QTL regions and identification of putative candidate genes for drought tolerance in rice. Mol. Gen. Genomics. 272: 35-46.

Passioura JB 2010 Scaling up: the essence of effective agricultural research. Funct. Plant Biol.37:585591.

Price A, Young EM and Tomos AD 1997 Quantitative trait loci associated with stomatal conductance, leaf rolling and heading date mapped in upland rice (Oryza sativa L.). New Phytol. 137:83-91.

Price AH, Steele KA, Moore BJ and Jones RGW 2002 Upland rice grown in soil-filled chambers and exposed to contrasting water deficit regimes. II. Mapping quantitative trait loci for root morphology and distribution. Field Crops Res. $76: 25-43$.

Price AH, Townend J, Jones MP, Audebert A and Courtois B 2002 Mapping QTLs associated with drought avoidance in upland rice grown in the Philippines and West Africa. Plant Mol. Biol.48:683-695.

Quarrie SA, Gulli M, Calestani C, Steed A and Marmiroli N 1994 Location of a gene regulating drought-induced abscisic acid production on the long arm of chromosome 5 A of wheat. Theor. Appl. Genet. 89: 794-800.

Quarrie SA, Laurie DA, Zhu J, Lebreton C and Semikhodskii A et al. 1997 QTL analysis to study the association between leaf size and abscisic acid accumulation in droughted rice leaves and comparisons across cereals. Plant Mol. Biol. 35: $155-165$.

Ranawake AL, Nakamura C, 2011 Development of a method for testing dehydration tolerance in rice (Oryza sativa L.) and its application to a recombinant inbred line population, Tropical Agriculture Research and Extension. 14 (3):76 $-83$

Ray JD, Yu L, McCouch SR, Champoux MC and Wang G et al. 1996 Mapping quantitative trait loci associated with root penetration ability in rice (Oryza sativa L.). Theor. Appl. Genet.
92:627-636.

Robin S, Pathan MS, Courtois B, Lafitte R, Carandang S, Lanceras S, Amante M, Nguyeen HT and Li Z 2003Mapping osmotic adjustment in an advanced back-cross inbred population of rice. Theor. Appl. Genet.107: 1288-1296.

Schroeder JI, Kwak JM and Allen GJ 2001 Guard cell abscisic acid signalling and engineering drought hardiness in plants. Nature. 410: 327330.

Sharp RE, Poroyko V, Hejlek LG, Spollen WG, Springer GK, Bohnert HJ and Nguyen HT 2004 Root growth maintenance during water deficits: physiology to functional genomics. J. Exp. Bot. 55: 2343-2351.

Sinclair TR 2011 Challenges in breeding for yield increase for drought. Trends Plant Sci.16:289293.

Trypathy JN, Zang J, Robin S, Nguyen TT and Nguyen HT 2000 QTLs for cell-membrane stability mapped in rice (Oryza sativa L.) under drought stress. Theor. Appl. Genet. 100: 1197-1202.

Wang HI, Kamoshita Y, Wade A, Siopongco L, Nguyen J and Yamauchi HA 2004 QTL analysis on plasticity in lateral root development in response to water stress in the rice plant Rice is life: scientific perspectives for the 21 st century. In: Proceedings of the World Rice Research Conference ,Tsukuba, Japan, Toriyama K, Heong KL, Hardy B (ed.).

Wang S, Basten CJ, Gaffney P and Zeng ZB 2003 Windows QTL Cartographer Version 2.0. Statistical Genetics, North Carolina State University, USA.

Wang X-S, Zhu J, Mansueto L and Bruskiewich R 2005 Identification of candidate genes for drought stress tolerance in rice by the integration of a genetic (QTL) map with the rice genome physical map. J. Zhejiang Univ. Sci. B. 6 (5): 382-388.

Xiong L, Wang R-U, Mao G and Koczan JM 2006 Identification of Drought Tolerance Determinants by Genetic Analysis of Root Response to Drought Stress and Abscisic Acid. Plant Physiology. 142(3):1065-1074.

Yadav R, Courtois B, Huang N and McLaren G 1997 Mapping genes controlling root morphology and root distribution in a doubled-haploid population of rice. Theor. Appl. Genet. 94:619632.

Yue B, Xue W, Xiong L, Yu X, Luo L, Cui K, Jin J, Xing Y and Zhang Q 2006 Genetic Basis of Drought Resistance at Reproductive Stage in Rice: Separation of Drought Tolerance From Drought Avoidance. Genetics. 172: $1213-1228$. 
Tropical Agricultural Pesearch \& Extension 15(4): 2012

Yue B, Xue W, Luo L and Xing JY 2008 Identification of quantitative trait loci for four morphologic traits under water stress in rice (Oryza sativa L.). Genet.Genomics. 35: 569-575.

Zeng H, Zhong Y and Luo L 2006 Drought tolerance genes in rice. Funct. Integr. Genomics. 6: 338-341.

Zhang J, Zheng HG, Aarti A, Pantuwan G and Nguyen TT et al. 2001 Locating genomic regions associated with components of drought resistance in rice: comparative mapping within and across species. Theor. Appl. Genet. 103: 19-29.
Zhang J, Nguyen HT and Blum A 1999 Genetic analysis of osmotic adjustment in crop plants. J. Exp. Bot. 50: 291-302.

Zheng HG, Babu RC, Pathan MS, Ali L and Huang N et al. 2000 Quantitative trait loci for root-penetration ability and root thickness in rice: comparison of genetic backgrounds. Genome. 43: 53-61. 